Shivanthan Shanthikumar ORCID iD: 0000-0001-6000-3180

\title{
Interventional Bronchoscopy in Children; Planning the Path Ahead
}

Authors; Shivanthan Shanthikumar, MBBS ${ }^{1,2,3}$, Daniel Steinfort, PhD ${ }^{4,5}$, Sarath Ranganathan, $\mathrm{PhD}{ }^{1,2,3}$

\section{Institutes;}

1. Respiratory and Sleep Medicine, Royal Children's Hospital, Melbourne, Australia

2. Department of Paediatrics, University of Melbourne, Melbourne, Australia

3. Respiratory Diseases, Murdoch Children's Research Institute, Melbourne,

Australia

4. Respiratory and Sleep Medicine, Royal Melbourne Hospital, Parkville, Australia

5. Department of Medicine, Royal Melbourne Hospital, The University of Melbourne, Parkville, VIC, Australia

Corresponding Author; Dr Shivanthan Shanthikumar; Respiratory Medicine, Royal Children's Hospital, 50 Flemington Road, Parkville, VIC, 3052, Australia;

shivanthan.shanthikumar@rch.org.au

Word Count; 1390

Conflict of Interest; Dr Shanthikumar, Dr Steinfort and Prof Ranganathan have no conflicts of interests to declare.

This is the author manuscript accepted for publication and undergone full peer review but has not been through the copyediting, typesetting, pagination and proofreading process, which may lead to differences between this version and the Version of Record. Please cite this article as doi: 10.1002/ppul.24596.

This article is protected by copyright. All rights reserved. 


\section{Interventional Bronchoscopy in Children; Planning the Path Ahead}

Recently published in the journal is an editorial by Burks et al ${ }^{1}$ regarding the use of endobronchial ultrasound-guided trans- bronchial needle aspiration (EBUS-TBNA) and endoscopic ultrasound with transesophageal endobronchoscope-guided fine needle aspiration (EUS-B-FNA) in the pediatric population. The editorial provides a thoughtful analysis of the article by Gulla et al $^{2}$ that described a case series of these procedures in children, as well as analysis of other published evidence in the area. In particular, the editorial reviews the promising but limited data available in children regarding EBUS procedures, concerns regarding indications and safety of such procedures. We recently published a case series which further contributes to the evidence base regarding EBUS-TBNA in children, showing good diagnostic yield and no adverse events. ${ }^{3}$ Burks et al also highlights difficulties training pediatric pulmonologists to perform EBUS procedures given the limited number of appropriate cases in children. The concerns raised by Burks et al regarding indications and safety for EBUS and adequate training have also been raised in guidelines published by the American Thoracic Society ${ }^{4}$ and European Respiratory Society ${ }^{5}$. However, to answer the question posed by the title of the editorial "Should endoscopic ultrasound-guided biopsies for mediastinal abnormalities be performed by pediatric pulmonologists?” we feel that a broader view of the field of interventional bronchoscopy needs to be taken. We think that decisions regarding the potential utility of EBUS in children, and the way to identify and define this, should not be made in isolation but together with consideration of other interventional bronchoscopy techniques and their potential application in children. In this editorial we briefly review the current state of interventional bronchoscopy in adults and children, and outline a potential path for advancement of the field in pediatric practice.

The current field of interventional bronchoscopy in adult medicine encompasses a number of procedures. As described by Burks et al EBUS-TBNA ${ }^{6}$ and EUS-B-FNA ${ }^{7}$ are now first line investigations for mediastinal pathology in adults. When sampling mediastinal pathology a dedicated linear EBUS bronchoscope, which has a linear ultrasound transducer fixed to the end of it, is used and this allows real time EBUS guided TBNA. ${ }^{8}$ Radial EBUS is another established modality. In radial EBUS a conventional bronchoscope is used and an ultrasound probe, often enclosed within a

This article is protected by copyright. All rights reserved. 
guide sheath, is passed via the working channel. The images from the probe are used to localise peripheral pathology and then the probe is withdrawn, with the guide sheath left in place, and a biopsy is then taken. ${ }^{8}$ Radial EBUS is the first choice investigation for investigation of peripheral pathology, where the linear bronchoscope is too large to access the location of the lesion. ${ }^{9}$ Another interventional bronchoscopic technique is the placement of endobronchial valves. In this technique a valve, which allows expiration of air from the treated lobe but not reinflation, is placed via a bronchoscope to facilitate lung volume reduction in conditions characterised by hyperinflation (such as emphysema). ${ }^{10}$ They are also used in patients who have a persistent air leak. ${ }^{11}$ Cryoprobe is also used in adult interventional bronchoscopy. It is a probe which can be passed via the working channel of a bronchoscope. The probe rapidly cools the target area to $-80^{\circ}$ Celsius which then allows a transbronchial biopsy to be taken. Cryoprobe biopsies are being used in interstitial lung disease (ILD), where they are safer than surgical lung biopsy, however the optimal use of this technology for ILD remains a point of contention due to conflicting evidence regarding the yield of cryoprobe biopsy when compared to surgical biopsy. ${ }^{12,13}$ They can also be used for removal of foreign body as when the probe rapidly cools it attaches to the foreign body and then can retrieve it. ${ }^{14}$ Other techniques which are not as widely used include bronchial thermoplasty (primarily used in severe asthma) ${ }^{15-17}$ and probe-based confocal laser endomicroscopy imaging of airways and alveoli (a new technique under development) ${ }^{18-20}$.

Like linear EBUS-TBNA and EUS-B-FNA all of the techniques that are widely used in adult practice, have the potential to be applied to pediatric practice. In fact many of them already are being used. The authors recently reported a small series of radial EBUS cases from Australia and Germany where it was technically feasible, however had poor results. ${ }^{3}$ Another recent series of 18 radial EBUS cases from North America in immunocompromised children showed no major complications and that is was useful in identifying the infectious aetiology of lung nodules. ${ }^{21}$ Cryoprobes have been used in the investigation of childhood $\operatorname{ILD}^{22}$, as well as for the removal of foreign body $^{23,24}$. Endobronchial valves have been used in the management of children with persistent air leak. ${ }^{25,26}$

This article is protected by copyright. All rights reserved. 
Given multiple techniques are already being used, moving forward, the field of interventional pediatric bronchoscopy will need to define the optimal use of each technique in children. To determine this for any individual technique the indications, feasibility, yield, and safety all need to be considered. We believe determining the optimal use of the various interventional bronchoscopy techniques should involve partnership between pediatric and adult pulmonologists, specific, focused education of pediatric pulmonologists and establishment of an international registry.

As Burks et al mention, it will be impossible to train for EBUS in the pediatric setting, and this issue is amplified when you consider the range of procedures that may be applicable to children. In addition, given each individual procedure is likely to be performed rarely at any one institution, it is unlikely a paediatrician will be able to maintain their competency across the different procedures. It is the authors opinion that pediatric centres will need to partner with adult interventional bronchoscopists who will perform the procedures. The role of the pediatric pulmonolgists would be to identify cases, provide expertise on potential pathology and how that may influence sampling technique and ensure safe airway management and perioperative care for patients. Even for the rare pediatric centres which have a large enough case number to maintain skills in the various techniques, it would still be of benefit to be partnered with an adult service as this ensures any new techniques or technology can be translated to pediatric practice as appropriate.

Education of pediatric pulmonologists is crucial so that they know what less invasive procedures are possible. A potential framework for such education is a workshop that was led by the authors as part of the American Thoracic Society Pediatric Fellows Track Symposium this year. The workshop, which focused on both linear and radial EBUS, involved a short didactic session, including case presentation, and then a hands-on practical demonstration on models. In addition to education content, the workshop also modelled a positive working relationship between adult and pediatric pulmonologists. The feedback received from participants in the workshop was very positive and indicates strong interest in this field. Pre- and post-workshop surveys showed that participation in the workshop improved understanding of the potential uses and limitations of EBUS in pediatric patients.

This article is protected by copyright. All rights reserved. 
The field of interventional bronchoscopy in adults is supported by a strong evidence base, with many techniques supported by evidence gained through randomised control trials $^{15,16,27,28}$ and meta-analyses ${ }^{29-31}$ showing the superior performance when compared to alternate techniques. Given the small number of cases in paediatrics it is unlikely it will be possible to conduct similar trials. Currently the literature in this area is made up of case reports and case series, with a high potential for publication bias. We propose that a potential way around this would be the establishment of an international registry where pulmonologists could enter case information regarding indication for procedure (including information regarding lesion location and size, other investigations), technical information regarding the procedure (technique, equipment, airway adjunct, adult vs. pediatric bronchoscopist), safety data, yield, and effect on patient management. In adult interventional bronchoscopy national level registries have helped generate evidence to inform clinical practice. ${ }^{32-34}$ In paediatrics, the registry should be open internationally given that the case series reported this far have come from India ${ }^{2,22,35-37}$, China ${ }^{23}$, United States of America ${ }^{24,25,38}$, the Netherlands $^{26}$, Germany $^{3}$ and Australia ${ }^{3,39}$. Establishment of such a registry likely represents the most pragmatic way to generate evidence regarding the use of the different interventional bronchoscopy techniques.

The field of pediatric interventional bronchoscopy is at an exciting point where there are currently reports in the literature of various techniques being performed which spare children from more invasive procedures. Important consideration needs to be given to how we advance the field and define the optimal use of each technique. We believe the way to do this is via partnership with adult services, broader education of pediatric pulmonologists and establishment of an international registry. If these steps are taken, we believe that, like adult interventional bronchoscopy, pediatric interventional bronchoscopy can be enhanced by an evidence base that contributes to better care delivered to patients.

This article is protected by copyright. All rights reserved. 


\section{References}

1. Burks AC, Vece T, Akulian J. Should endoscopic ultrasound-guided biopsies for mediastinal abnormalities be performed by pediatric pulmonologists? Pediatric Pulmonology;0(0).

2. Gulla KM, Gunathilaka G, Jat KR, Sankar J, Karan M, Lodha R, Kabra SK. Utility and safety of endobronchial ultrasound-guided transbronchial needle aspiration and endoscopic ultrasound with an echobronchoscope-guided fine needle aspiration in children with mediastinal pathology. Pediatric Pulmonology;0(0).

3. Shanthikumar S, Massie J, Ranganathan S, Schuhmann M, Eberhardt R, Irving LB, Herth FJF, Steinfort DP. Utility of Endobronchial Ultrasound in Assessment of Intrathoracic Lesions in Paediatric Patients. Respiration 2019:1-7.

4. Faro A, Wood RE, Schechter MS, Leong AB, Wittkugel E, Abode K, Chmiel JF, Daines C, Davis S, Eber E and others. Official American Thoracic Society Technical Standards: Flexible Airway Endoscopy in Children. American Journal of Respiratory and Critical Care Medicine 2015;191(9):1066-1080.

5. Eber E, Anton-Pacheco JL, de Blic J, Doull I, Faro A, Nenna R, Nicolai T, Pohunek P, Priftis KN, Serio P and others. ERS statement: interventional bronchoscopy in children. Eur Respir J 2017;50(6).

6. Wahidi MM, Herth F, Yasufuku K, Shepherd RW, Yarmus L, Chawla M, Lamb C, Casey KR, Patel S, Silvestri GA and others. Technical Aspects of Endobronchial Ultrasound-Guided Transbronchial Needle Aspiration: CHEST Guideline and Expert Panel Report. CHEST 2016;149(3):816-835.

7. Vilmann P, Clementsen PF, Colella S, Siemsen M, De Leyn P, Dumonceau JM, Herth FJ, Larghi A, Vazquez-Sequeiros E, Hassan C and others. Combined endobronchial and esophageal endosonography for the diagnosis and staging of lung cancer: European Society of Gastrointestinal Endoscopy (ESGE) Guideline, in cooperation with the European Respiratory Society (ERS) and the European Society of Thoracic Surgeons (ESTS). Endoscopy 2015;47(6):545-59.

8. Steinfort DP, Wurzel D, Irving LB, Ranganathan SC. Endobronchial ultrasound in pediatric pulmonology. Pediatr Pulmonol 2009;44(4):303-8.

9. Schuhmann M, Eberhardt R, Herth FJ. Endobronchial ultrasound for peripheral lesions: a review. Endosc Ultrasound 2013;2(1):3-6.

10. Hartman JE, Vanfleteren LEGW, van Rikxoort EM, Klooster K, Slebos D-J. Endobronchial valves for severe emphysema. European Respiratory Review 2019;28(152):180121.

This article is protected by copyright. All rights reserved. 
11. Fiorelli A, D'Andrilli A, Cascone R, Occhiati L, Anile M, Diso D, Cassiano F, Poggi $C$, Ibrahim $M$, Cusumano $G$ and others. Unidirectional endobronchial valves for management of persistent air-leaks: results of a multicenter study. J Thorac Dis 2018;10(11):6158-6167.

12. Tomassetti S, Wells AU, Costabel U, Cavazza A, Colby TV, Rossi G, Sverzellati $\mathrm{N}$, Carloni A, Carretta E, Buccioli M and others. Bronchoscopic Lung Cryobiopsy Increases Diagnostic Confidence in the Multidisciplinary Diagnosis of Idiopathic Pulmonary Fibrosis. Am J Respir Crit Care Med 2016;193(7):74552.

13. Romagnoli M, Colby TV, Berthet JP, Gamez AS, Mallet JP, Serre I, Cancellieri A, Cavazza A, Solovei L, Dell'Amore A and others. Poor Concordance between Sequential Transbronchial Lung Cryobiopsy and Surgical Lung Biopsy in the Diagnosis of Diffuse Interstitial Lung Diseases. Am J Respir Crit Care Med 2019;199(10):1249-1256.

14. Sriratanaviriyakul N, Lam F, Morrissey BM, Stollenwerk N, Schivo M, Yoneda KY. Safety and Clinical Utility of Flexible Bronchoscopic Cryoextraction in Patients With Non-neoplasm Tracheobronchial Obstruction: A Retrospective Chart Review. J Bronchology Interv Pulmonol 2015;22(4):288-93.

15. Cox G, Thomson NC, Rubin AS, Niven RM, Corris PA, Siersted HC, Olivenstein $\mathrm{R}$, Pavord ID, McCormack D, Chaudhuri R and others. Asthma control during the year after bronchial thermoplasty. N Engl J Med 2007;356(13):1327-37.

16. Pavord ID, Cox G, Thomson NC, Rubin AS, Corris PA, Niven RM, Chung KF, Laviolette M. Safety and efficacy of bronchial thermoplasty in symptomatic, severe asthma. Am J Respir Crit Care Med 2007;176(12):1185-91.

17. Wechsler ME, Laviolette M, Rubin AS, Fiterman J, Lapa e Silva JR, Shah PL, Fiss $E$, Olivenstein R, Thomson NC, Niven RM and others. Bronchial thermoplasty: Long-term safety and effectiveness in patients with severe persistent asthma. J Allergy Clin Immunol 2013;132(6):1295-302.

18. Shafiek H, Fiorentino F, Cosio BG, Kersul A, Thiberville L, Gómez C, Riera M, Martín ML, Martínez R, Noguera MA. Usefulness of bronchoscopic probebased confocal laser endomicroscopy in the diagnosis of Pneumocystis jirovecii pneumonia. Respiration 2016;92(1):40-47.

19. Shah PL, Kemp SV, Newton RC, Elson DS, Nicholson AG, Yang GZ. Clinical Correlation between Real-Time Endocytoscopy, Confocal Endomicroscopy, and Histopathology in the Central Airways. Respiration 2017;93(1):51-57.

20. Wellikoff AS, Holladay RC, Downie GH, Chaudoir CS, Brandi L, Turbat-Herrera EA. Comparison of in vivo probe-based confocal laser endomicroscopy with histopathology in lung cancer: A move toward optical biopsy. Respirology 2015;20(6):967-974.

This article is protected by copyright. All rights reserved. 
21. Bouso JM, Yendur O, Hysinger E, Planet PJ, Haas A, Goldfarb S, Piccione J. EBUS Guided Biopsy is Feasible, Safe, and Improves Diagnostic Yields in Immunocompromised Children. Am J Respir Crit Care Med 2019.

22. Srikanta JT, Swarna S, Shylendra DS, Mehta R. Transbronchial Lung Cryobiopsy for Diagnosis of Pediatric Interstitial Lung Disease. Indian Pediatr 2018;55(6):519-520.

23. Zhang L, Yin Y, Zhang J, Zhang H. Removal of foreign bodies in children's airways using flexible bronchoscopic $\mathrm{CO} 2$ cryotherapy. Pediatr Pulmonol 2016;51(9):943-9.

24. David AP, Xu MJ, Rosbe KW, Meyer AK, Gesthalter YB, Chan DK. Cryoprobe retrieval of an airway foreign body: A case report and literature review. Int J Pediatr Otorhinolaryngol 2019;125:79-81.

25. Toth JW, Podany AB, Reed MF, Rocourt DV, Gilbert CR, Santos MC, Cilley RE, Dillon PW. Endobronchial occlusion with one-way endobronchial valves: a novel technique for persistent air leaks in children. J Pediatr Surg 2015;50(1):82-5.

26. Jaspers GJ, Willemse BWM, Kneyber MCJ. Endobronchial valve placement for a severe pneumothorax in a child on ECLS. Pediatr Pulmonol 2019.

27. Criner GJ, Sue R, Wright S, Dransfield M, Rivas-Perez H, Wiese T, Sciurba FC, Shah PL, Wahidi MM, de Oliveira HG. A multicenter randomized controlled trial of Zephyr endobronchial valve treatment in heterogeneous emphysema (LIBERATE). American journal of respiratory and critical care medicine 2018;198(9):1151-1164.

28. von Bartheld MB, Dekkers OM, Szlubowski A, Eberhardt R, Herth FJ, in 't Veen JC, de Jong YP, van der Heijden EH, Tournoy KG, Claussen M and others. Endosonography vs conventional bronchoscopy for the diagnosis of sarcoidosis: the GRANULOMA randomized clinical trial. Jama 2013;309(23):2457-64.

29. Dong X, Qiu X, Liu Q, Jia J. Endobronchial ultrasound-guided transbronchial needle aspiration in the mediastinal staging of non-small cell lung cancer: a meta-analysis. Ann Thorac Surg 2013;96(4):1502-1507.

30. Low SW, Lee JZ, Desai H, Hsu CH, Sam AR, Knepler JL. Endobronchial Valves Therapy for Advanced Emphysema: A Meta-Analysis of Randomized Trials. J Bronchology Interv Pulmonol 2019;26(2):81-89.

31. Steinfort DP, Khor YH, Manser RL, Irving LB. Radial probe endobronchial ultrasound for the diagnosis of peripheral lung cancer: systematic review and meta-analysis. Eur Respir J 2011;37(4):902-10.

This article is protected by copyright. All rights reserved. 
32. Burn J, Sims AJ, Patrick H, Heaney LG, Niven RM. Efficacy and safety of bronchial thermoplasty in clinical practice: a prospective, longitudinal, cohort study using evidence from the UK Severe Asthma Registry. BMJ Open 2019;9(6):e026742.

33. Eapen GA, Shah AM, Lei X, Jimenez CA, Morice RC, Yarmus L, Filner J, Ray C, Michaud G, Greenhill SR and others. Complications, consequences, and practice patterns of endobronchial ultrasound-guided transbronchial needle aspiration: Results of the AQuIRE registry. Chest 2013;143(4):1044-1053.

34. Skowasch D, Fertl A, Schwick B, Schafer H, Hellmann A, Herth FJ. A Long-Term Follow-Up Investigation of Endobronchial Valves in Emphysema (the LIVE Study): Study Protocol and Six-Month Interim Analysis Results of a Prospective Five-Year Observational Study. Respiration 2016;92(2):118-26.

35. Dhooria S, Madan K, Pattabhiraman V, Sehgal IS, Mehta R, Vishwanath G, Srinivasan A, Sivaramakrishnan M, Mohan A, Mathew JL and others. A multicenter study on the utility and safety of EBUS-TBNA and EUS-B-FNA in children. Pediatr Pulmonol 2016;51(10):1031-1039.

36. Madan K, Dhungana A, Mohan A, Hadda V, Jain D, Arava S, Pandey RM, Khilnani GC, Guleria R. Conventional Transbronchial Needle Aspiration Versus Endobronchial Ultrasound-guided Transbronchial Needle Aspiration, With or Without Rapid On-Site Evaluation, for the Diagnosis of Sarcoidosis: A Randomized Controlled Trial. J Bronchology Interv Pulmonol 2017;24(1):4858.

37. Madan K, Garg P, Kabra SK, Mohan A, Guleria R. Transesophageal Bronchoscopic Ultrasound-guided Fine-needle Aspiration (EUS-B-FNA) in a 3Year-Old Child. J Bronchology Interv Pulmonol 2015;22(4):347-50.

38. Gilbert CR, Chen A, Akulian JA, Lee HJ, Wahidi M, Argento AC, Tanner NT, Pastis NJ, Harris K, Sterman D and others. The use of convex probe endobronchial ultrasound-guided transbronchial needle aspiration in a pediatric population: a multicenter study. Pediatr Pulmonol 2014;49(8):80715.

39. Wurzel DF, Steinfort DP, Massie J, Ryan MM, Irving LB, Ranganathan SC. Paralysis and a perihilar protuberance: an unusual presentation of sarcoidosis in a child. Pediatr Pulmonol 2009;44(4):410-4.

This article is protected by copyright. All rights reserved. 


\section{University Library}

\section{- M M I N E R VA A gateway to Melbourne's research publications}

Minerva Access is the Institutional Repository of The University of Melbourne

Author/s:

Shanthikumar, S;Steinfort, DP;Ranganathan, S

Title:

Interventional bronchoscopy in children: Planning the path ahead

Date:

2019-12-09

Citation:

Shanthikumar, S., Steinfort, D. P. \& Ranganathan, S. (2019). Interventional bronchoscopy in children: Planning the path ahead. PEDIATRIC PULMONOLOGY, 55 (2), pp.288-291. https:// doi.org/10.1002/ppul.24596.

Persistent Link:

http://hdl.handle.net/11343/286721 